Raju Dandu, Kansas State University-Salina 


\title{
Design of Energy Efficient Recessed Compact Fluorescent (CFL) Downlight Fixture
}

\author{
Dr. Raju Dandu, Associate Professor \\ Mechanical Engineering Technology \\ Kansas State University at Salina
}

\begin{abstract}
A recessed downlight is designed to address limited availability of energy efficient residential and light commercial recessed downlight fixtures. This fixture is a non-conventional indoor insulated ceiling (IC) rated, air-tight recessed compact fluorescent lamp (CFL) downlight fixture. The distinct features of fixture include: compact and light weight, unique CFL lamp, built-inmodularity and high lumen output. This paper outlines the design and development of a recessed downlight to address the early market acceptance of CFL fixtures and the replacement of incandescent light sources.
\end{abstract}

\section{Introduction}

United States Government agencies and electric utilities are actively promoting the market transformation of energy efficient residential light fixtures. A major impediment to these promotions is the lack of performance and affordable price of these light fixtures. Given the market size and the number of "off the shelf" technology solutions, Department of Energy (DOE) sees a significant opportunity to improve the energy efficiency of recessed CFL downlights. There is a dire need to develop a CFL downlight that will effectively resolve the existing issues of competitive cost, high lumen output, and performance problems due to high temperatures.

\section{Background of Product Development}

The barriers to successful commercial introduction and early market acceptance of recessed compact fluorescent lamp (CFL) downlights are known. Ecos Consulting, Benya Lighting Design, Rising Sun Enterprises (2002) market research report stated that the barriers are:

- relative high price

- limited market availability

- limited high lumen output

- $\quad$ performance problems such as reduced lumen output, lamp life, and ballast life from high temperatures

- lack of easy access for component replacement

Improvements in CFL technology, innovative designs, manufacturing, and distribution can reduce or minimize several of these barriers. A less expensive, efficient and attractive with improved quality, a properly designed recessed CFL downlight fixture can resolve the above concerns and there by can significantly influence acceptance of market penetration over incandescent recessed downlight fixtures. If the recessed CFL downlight is well designed, 
providing value and performance for the price with standard or superior warranty, then the market transformation programs will have considerable success in promoting recessed CFL downlights. Ultimately, the intermediate buyers (retailers and electrical wholesalers; end user buyers such as public agencies and builders, as well as companies and organizations, electric utilities) will be greatly encouraged to accept all these features and market this product.

Almost every American home and light commercial facility uses electricity for lighting, so any improvement in lighting efficiency offers the potential to benefit the entire population. Studies done by Northwest Energy Efficiency Alliance indicate that use of electricity in residential/light commercial lighting is growing at least as fast as overall electricity demand. If a coordinated effort such as this market transformation program by Pacific Northwest National Laboratory (PNNL) is not successful, then lighting will remain a major cause for increased consumption of electricity.

Further more the demand for electricity to meet the lighting needs is continuing to rise, allowing increased energy bills, air pollution, and emissions of greenhouse gases. The fact is energy efficient lighting offers one of the best energy reduction opportunities. With efficient use of existing lighting technologies and controls, better residential/light commercial lighting design, better attention to energy efficient recessed CFL downlight fixtures, could cut the lighting electricity demand significantly and improve lighting service.

The proposed design of CFL downlight is an innovative, yet a unique indoor recessed CFL downlight to meet Pacific Northwest National Laboratory's (PNNL) objectives on market transformation of the downlights. Product M8-40IC/AT is expected to receive wide acceptance. Letter M represents Maya, 8" aperture opening, 40W double circline CFL lamp, IC for insulated ceiling and AT air-tight. Higher cost, limited lumen output, performance concerns, lack of customer awareness have posed serious barriers to the market transformation. The proposed design offers a unique non-conventional indoor insulated Ceiling (IC) rated, air-tight recessed CFL downlight fixture that is cost effective. M8-40IC/AT recessed CFL downlight uses a housing fixture with 9 in [229 mm] width, $7.5 \mathrm{in}[191 \mathrm{~mm}]$ height, and 8 in [203 mm] aperture, a 40W double circline lamp with 3000 initial lumens, a high frequency ON/OFF electronic ballast, an aluminum specular reflector and a plastic trim.

The proposed recessed CFL downlight is distinct from the designs currently available in the market. It is the best and most cost effective; it is simple, easy to install, and easy to access. Also it is easy to replace lamp, ballast, and other components. High lumen output, reduced spatial heating and cooling losses makes market transformation of recessed CFL downlight fixtures very viable.

\section{Description of M8-40IC/AT Recessed CFL Downlight Fixture}

The distinct features of fixture include:

- compact and lightweight (5lbs) [2.3 kg]

- unique and attractive lamp shape (double circline)

- built-in modularity 
- aesthetic

- high lumen output

The benefits of recessed CFL downlight include:

- less expensive and value for the price

- inherent safety

- easy to handle and install

- easy to replace components from within the interior living space

- fixture efficiency of 59.6\% (Fixture Efficiency-LM41-98 Test Results from Luminaire Testing Laboratory, Inc., Allentown, PA)

- air-tightness with 0.36 CFM air leakage

- reduced glare

- reduced spatial heating, cooling losses and energy savings

- long life and lighting quality (color and rendition)

The M8-40IC/AT indoor recessed CFL downlight fixture is designed for new residential/light commercial construction. Figure 1 shows the fixture and its major components: housing can, double circline CFL, on/off high frequency electronic ballast, aluminum reflector, and plastic trim. It is simple to install, light weight, modular, and aesthetic and provides comfort to the customer without sacrificing quality. The fixture is thermally protected and can be installed in direct contact with ceiling insulation. The airtight construction limits air exchange between the ceiling plenum and heated or air conditioned areas.

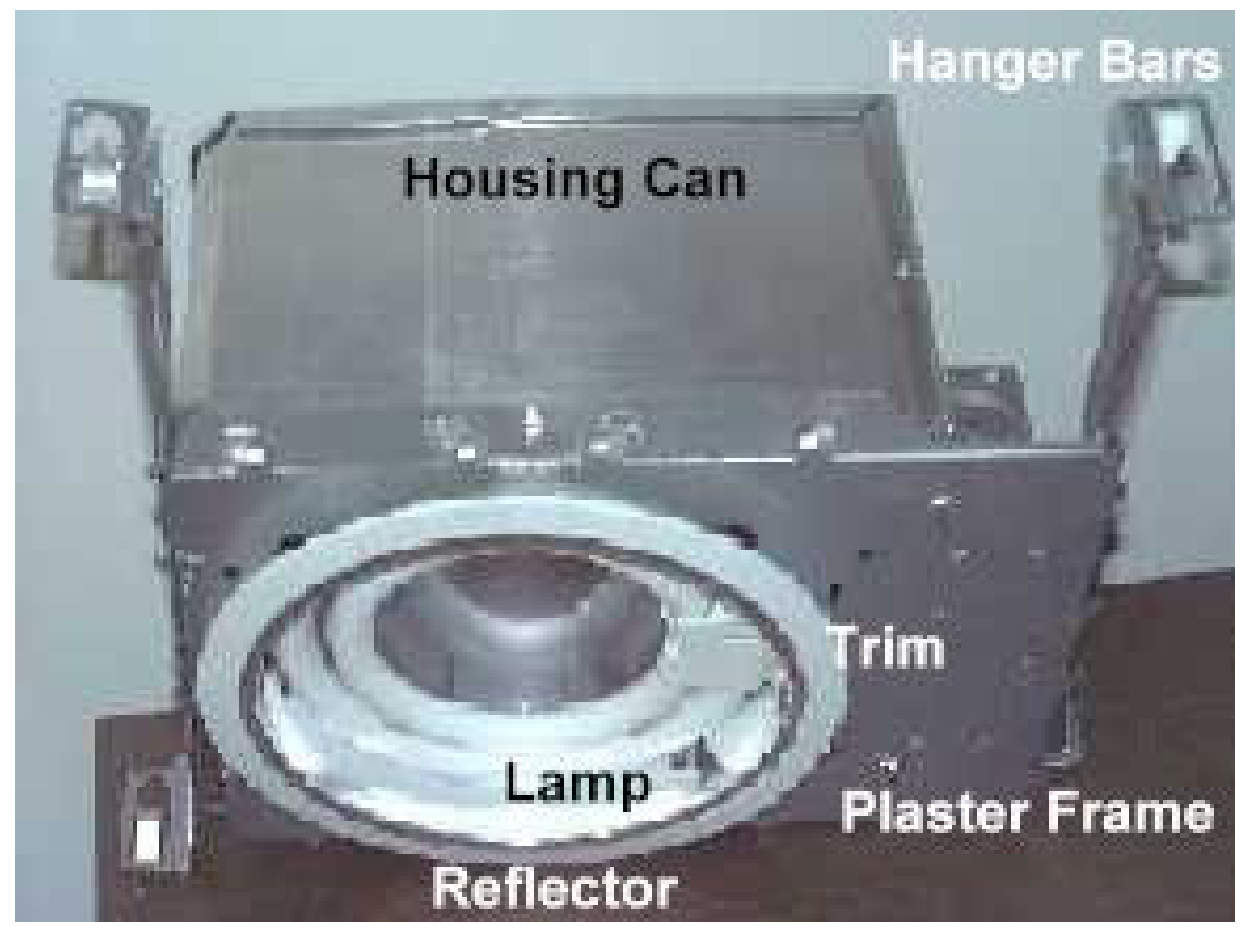

Figure 1. M8-40IC/AT Recessed Indoor CFL Luminaire

Proceedings of the 2006 American Society for Engineering Education Annual Conference \& Exposition 


\section{Housing Fixture}

The housing fixture is compact and designed for new construction, solid or suspended ceilings. The plaster frame is made of heavy-duty steel with overall dimensions 12.75 by 9.25 by 1 in [324 by 235 by $25 \mathrm{~mm}$ ] and with an aperture of 8 in [203 mm]. Four steel clips are mounted on the aperture flange to hold the reflector and provide adjustment for various ceiling thickness. Aluminum housing with 9 by 10.25 by 7 in [230 by 260 by $180 \mathrm{~mm}$ ] is secured to the plaster frame by perforated tabs. The field connection junction box is mounted on the plaster frame. Junction box with Snap-On covers and ground wire, built in Romex ${ }^{\circledR}$ clamps 0.5 in [12.5 mm] and $0.75 \mathrm{in}[19 \mathrm{~mm}]$ pry-outs provide for through branch circuit wiring. It has fully adjustable hanger bars from 14.25 in [362 $\mathrm{mm}$ ] minimum to 24.25 in [616mm] maximum. The bars can be positioned in either direction and the unique arrowhead design provides nail-less installation.

\section{Installation Features}

The housing fixture height of 7.5 in [190 mm] allows its use in 2 by 8 in [51 by $203 \mathrm{~mm}$ ] joist construction. Housing adjusts 0.75 in $[19 \mathrm{~mm}]$ to accommodate various ceiling thickness.

\section{Lamp}

Figure 2 shows single double circline compact fluorescent lamp with 4-pin GRY 10q-3 base. It is horizontally mounted for superior efficiency and visual comfort. The overall dimensions are 7.5 in [191 mm] outer diameter, 4.17 in [106 mm] inner diameter and a tube diameter of 0.75 in [20 $\mathrm{mm}]$. The lamp has 3000 initial lumens, CRI of 82 , and color temperature of $3000 \mathrm{~K}$.

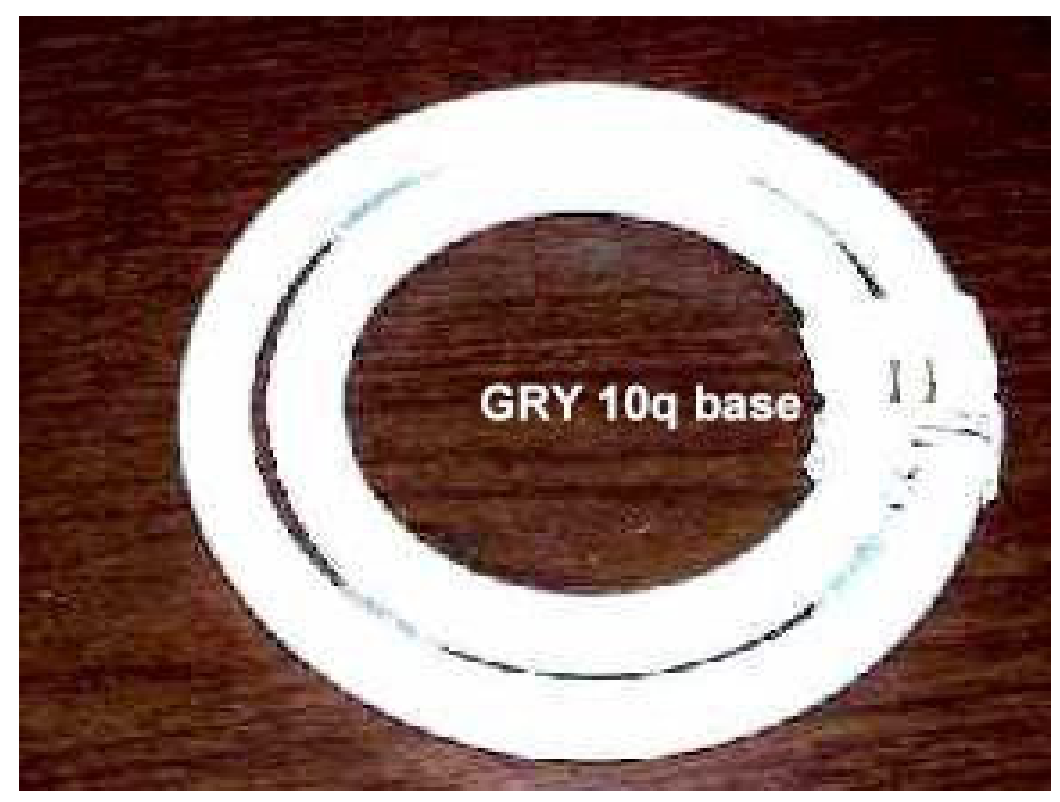

Figure 2. 40W Double Circline Lamp 


\section{Electronic Ballast}

High frequency on/off electronic ballast operates at 120v, $60 \mathrm{~Hz}$. It is prewired, class P normal power factor ballast. It has built-in safety feature against "end-of-lamp life". The 4-pin lamp socket wiring passes through a rubber grommet and a rubber tube and prewired to the ballast as shown in Figure 3. The ballast is mounted inside the aluminum housing on the inner Snap-On cover of the junction box with two screws. The ballast is connected to the power lines through a quick disconnect shown in fig.3. The ballast can be very easily reached through the aperture opening of the housing.

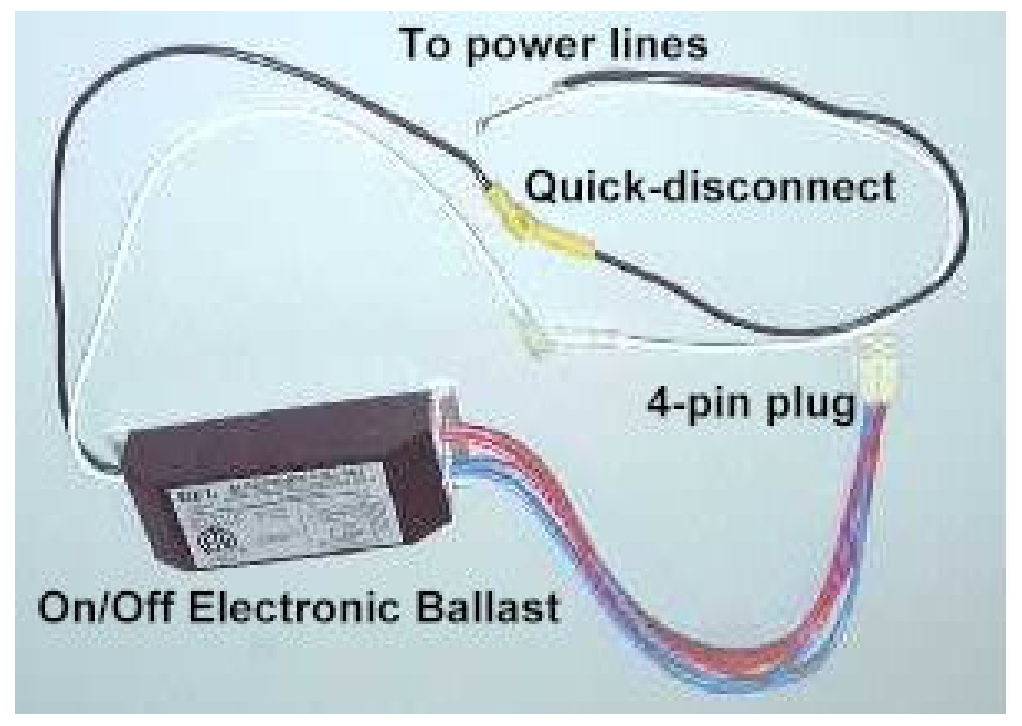

Figure 3. Electronic Ballast with Quick Disconnect

\section{Reflector and Trim Ring}

Aluminum reflector is clear specular with parabolic shape for optimum performance. The reflector measures $7.5 \mathrm{in}$ [191mm] of inner diameter at the face and 6.25 in [159mm] deep. The reflector has a 0.75 in [19 mm] opening on the side located at a height of 3 in $[75 \mathrm{~mm}]$ from the face. The opening allows wiring of the lamp socket for 4 pin lamp connector which is connected to the ballast shown in fig. 3 to pass through. The wiring is sealed in the opening with a rubber grommet and a rubber tube surrounding the wires. This insures air tightness. Both rubber grommet and tube withstand high temperatures. Three spring clips are riveted inside the reflector to hold the lamp horizontally. The trim ring is made of plastic.

\section{Conclusion}

Culture transformation from incandescent to energy efficient lighting products will benefit in reducing the electrical demand and reducing air pollution. The proposed recessed CFL downlight is distinct from the designs currently available in the market. In all most all commercially available recessed down light fixtures it is difficult to replace ballast from the living space. This particular design is modular and has unique feature which allows the electronic ballast replacement from the living space. The unique shape and placement of CFL lamp close to the 
proximity of the conditioned air of the interior of a room helps the lamp burn at its optimal temperature and consequently last close to the lamp design life. The lamp is placed horizontally and is close to the trim plane. Proximity to cooler interior ambient helps dissipate heat off the lamp. The hollow, annular space of this circline lamp helps further heat dissipation. Thus the temperature of the reflector does not get excessively hot. Lower wall temperature of the reflector is expected to keep the ballast case temperature lower than otherwise would be possible. This will consequently prolong the ballast life. It is simple, easy to install, and easy to access. Also it is easy to replace lamp, ballast, and other components. High lumen output, reduced spatial heating and cooling losses makes market transformation of recessed CFL downlight fixtures very viable.

As an educator I realized that this project provided an opportunity for learning outside the classroom. The interaction with industry, national laboratories, testing laboratories, and department of energy was enriching and educational. I am able to bring the experience to student design project course.

This product has to be further evaluated for optimal lumen output, lamp and ballast life, and various lamp ballast combinations.

\section{Bibliography}

1). Raju Dandu (2000). A Proposal for Supply of Recessed CFL Downlight in response to RFP \#406422, of November 22, 2000.

2). Residential New Construction Program, Market Research Summary Report, Prepared by Ecos Consulting, Benya Lighting Design, Rising Sun Enterprises, May 2002 from the World Wide Web:

http://www.nwalliance.org/resources/reportdetail.asp?RID $=90$

3). Energy Star Program Requirements for CFL from the World Wide Web:http://www.energystar.gov/ia/partners/product_specs/program_reqs/cfls_prog_req.pdf

4). Lighting Fixtures: Residential Recessed Downlights Technology Procurement from the World Wide Web: http://www.eere.energy.gov/buildings/emergingtech/pdfs/lighting_fixtures.pdf

\section{RAJU S. DANDU}

Raju S. Dandu is the program coordinator and an associate professor of Mechanical Engineering Technology at Kansas State University-Salina. He teaches courses in CNC Machine Processes, Material Strength and Testing, Advanced CAD/CAM, Industrial Instrumentation and Controls, and Automated Manufacturing Systems II. He is active in offering workforce training in reliability centered maintenance, process instrumentation and PLCs. His areas of interest are: Reliability Centered Maintenance, Energy Efficient Lighting, CAD/CAM, Industrial Automation, and Smart Materials. He is a member of ASEE, ASME, and SME. 